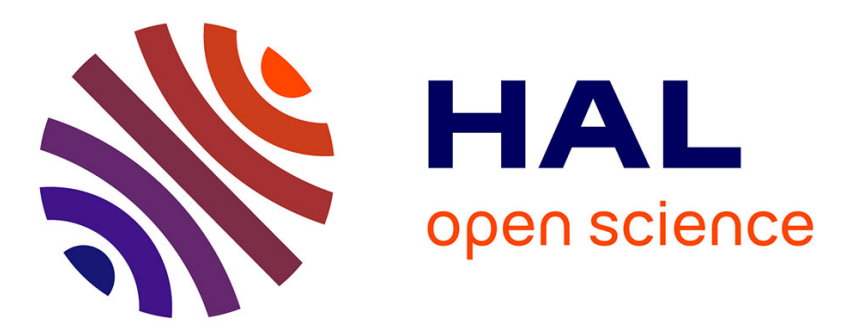

\title{
Errata - Chauffage ultra-rapide par dégagement contrôlé de la chaleur de mélange dans des composites de multicouches fines métal-métal
}

\author{
F. Bordeaux, A.R. Yavari, P. Desré
}

\section{- To cite this version:}

F. Bordeaux, A.R. Yavari, P. Desré. Errata - Chauffage ultra-rapide par dégagement contrôlé de la chaleur de mélange dans des composites de multicouches fines métal-métal. Revue de Physique Appliquée, 1987, 22 (11), pp.1599-1599. 10.1051/rphysap:0198700220110159901 . jpa-00245714

HAL Id: jpa-00245714

https://hal.science/jpa-00245714

Submitted on 1 Jan 1987

HAL is a multi-disciplinary open access archive for the deposit and dissemination of scientific research documents, whether they are published or not. The documents may come from teaching and research institutions in France or abroad, or from public or private research centers.
L'archive ouverte pluridisciplinaire HAL, est destinée au dépôt et à la diffusion de documents scientifiques de niveau recherche, publiés ou non, émanant des établissements d'enseignement et de recherche français ou étrangers, des laboratoires publics ou privés. 


\section{Errata}

(Revue Phys. Appl. 22 (1987) 707 et 775)

Les articles :

Chauffage ultra-rapide par dégagement contrôlé de la chaleur de mélange dans des composites de multicouches fines métal-métal

de F. Bordeaux, A. R. Yavari et P. Desré

paru dans la section Science des Matériaux du numéro d'août 87 ; 